\title{
Erratum to: Imaging findings of anterior hip dislocations
}

\author{
Kyle Pfeifer $^{1}$ - Michael Leslie ${ }^{2} \cdot$ Kirsten Menn $^{3} \cdot$ Andrew Haims $^{3}$
}

Published online: 13 March 2017

(C) ISS 2017

Erratum to: Skeletal Radiol

DOI 10.1007/s00256-017-2605-x

Figure captions 9 and 10 were reversed in the original article.

The correct figures and captions are indicated below:

The original article was corrected.

The online version of the original article can be found at http://dx.doi.org/ 10.1007/s00256-017-2605-x.

\footnotetext{
Kyle Pfeifer

kpfeife@gmail.com

Michael Leslie

Michael.leslie@yale.edu

Kirsten Menn

kirsten.menn@gmail.com

Andrew Haims

Andrew.haims@yale.edu

1 Department of Radiology, Mallinckrodt Institute of Radiology, 510

South Kings Highway Boulevard, St. Louis, MO, USA

2 Department of Orthopedics and Rehabilitation, Yale School of Medicine, 47 College Place, New Haven, CT 06520, USA

3 Department of Radiology and Biomedical Imaging, Yale University School of Medicine, 333 Cedar St, New Haven, CT 06520, USA
} 


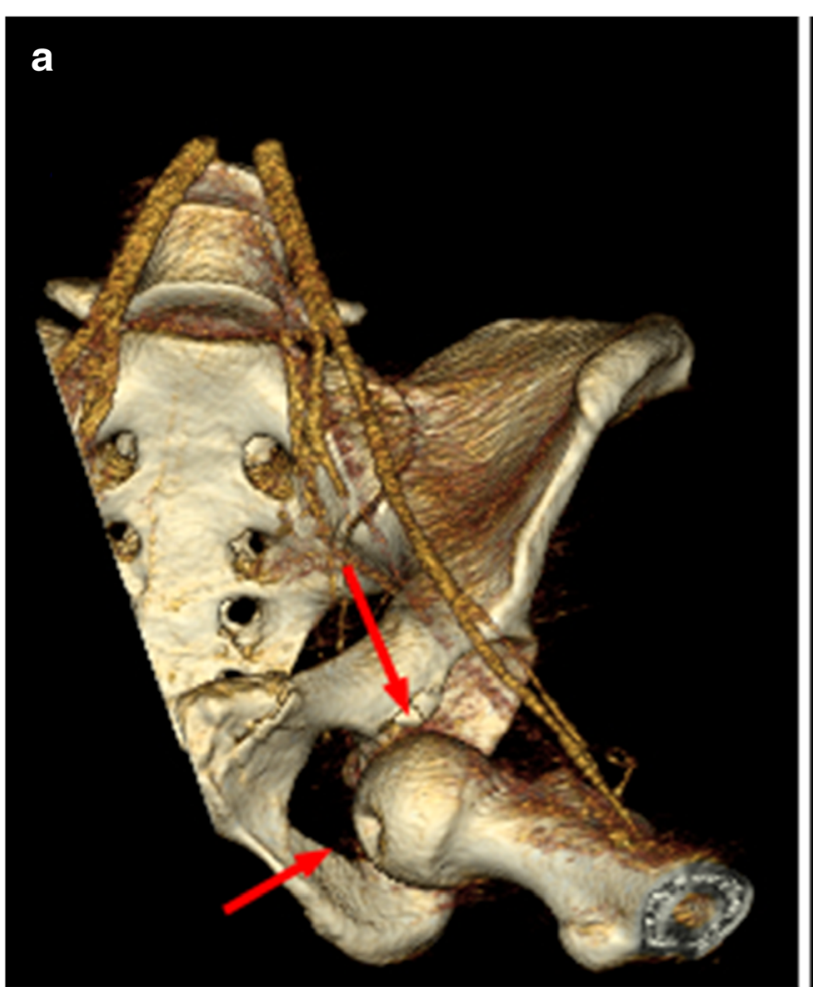

Fig. 9 A 27-year-old female status post motor vehicle accident. Figures are surface-rendered 3D images from CT of the pelvis using (Vitrea ${ }^{\circledR}$, Minnetonka, MN). a An anterior inferior dislocation of the

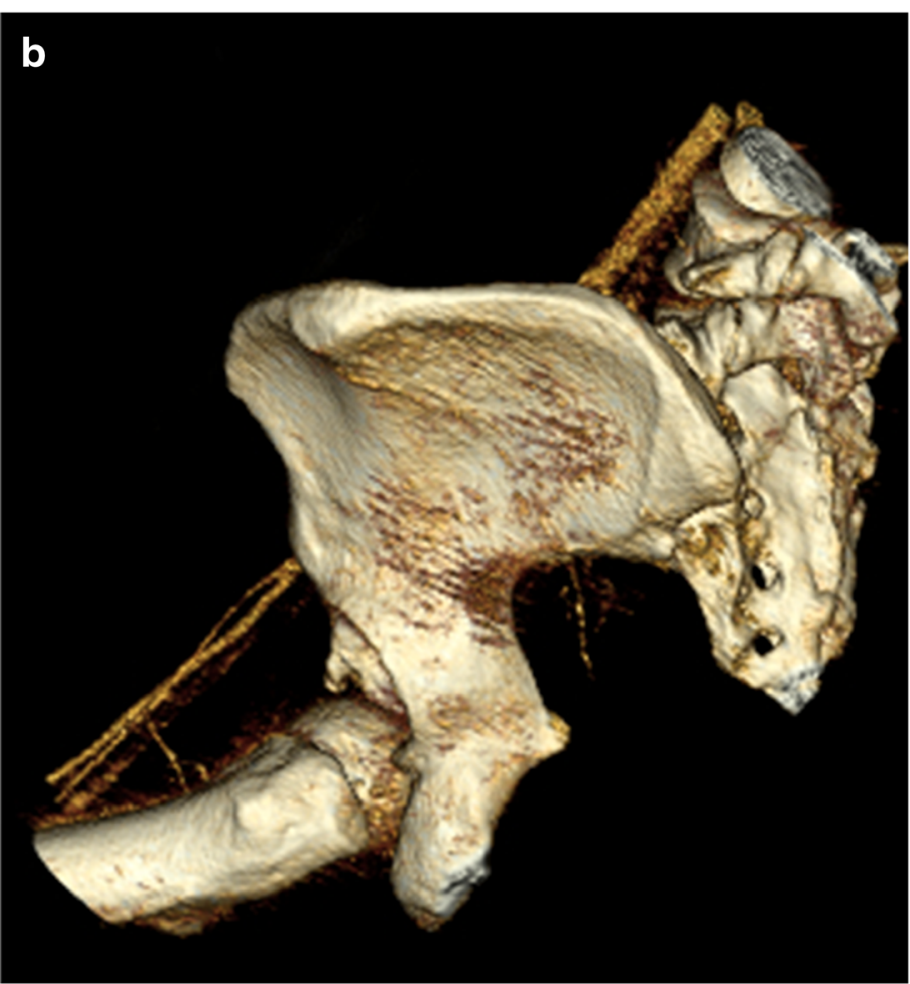

femoral head (red arrows) with the head resting over the left obturator foramen. b The patient's femoral head lodged within the obturator foramen

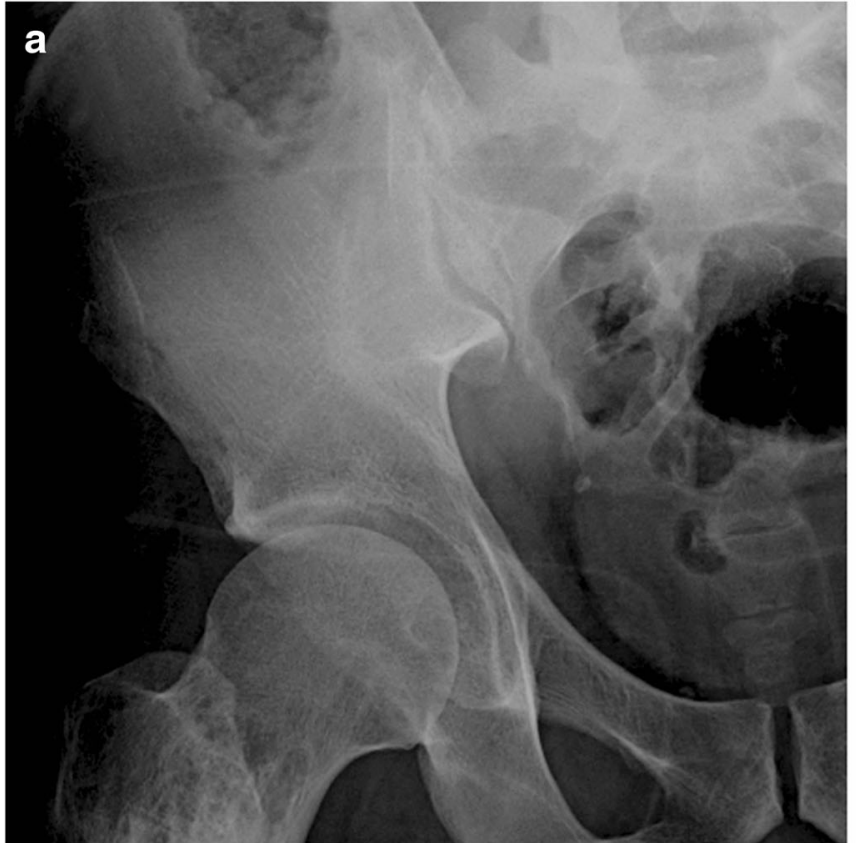

Fig. 10 Radiographs are 0 months (A: $Z=0.48), 5$ months $(B: Z=0.48)$, following an anterior inferior right hip dislocation. a Post reduction image. Five months later, the patient returned with pain. b Osteonecrosis and subchondral collapse (red arrows). Unfortunately,

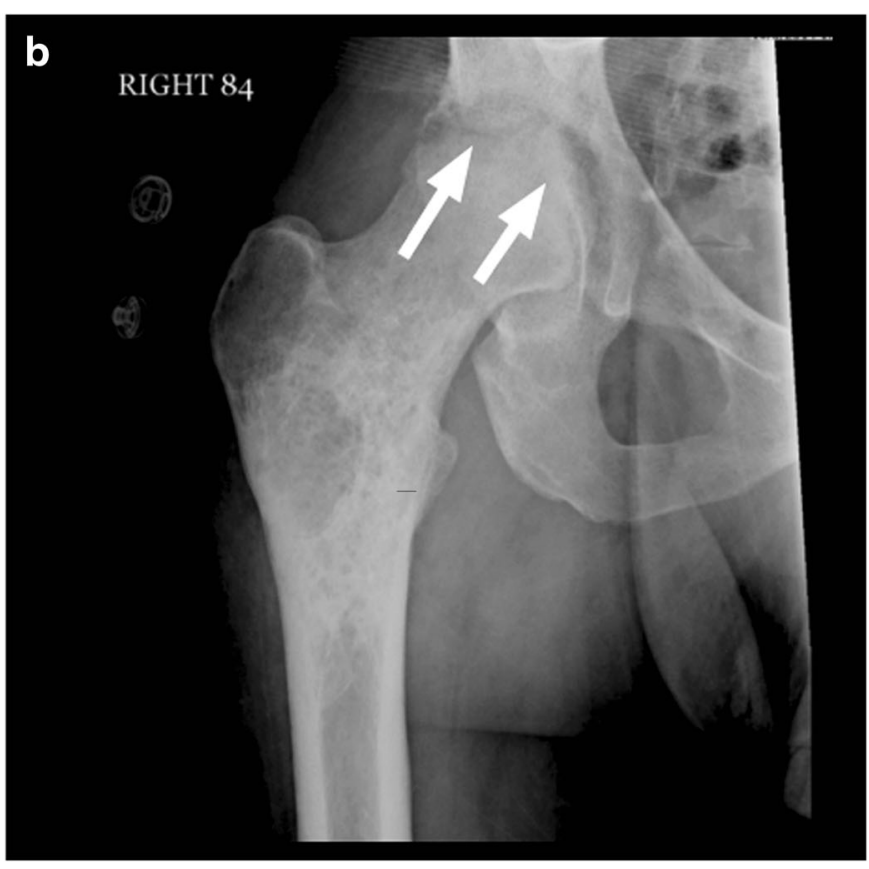

the patient had pain with ambulation and subsequently underwent right total hip arthroplasty Incidentally noted is a benign-appearing mixed sclerotic and lucent lesion in the proximal femur 